\title{
Mediyal ve lateral malleol kırıklarında cerrahi yaklaşımlar
}

\author{
Surgical approaches for the fractures of the medial and lateral malleolus
}

\author{
Ali Turgut ${ }^{1}$, Uğur Gönç² \\ ${ }^{1}$ Tepecik Eğitim ve Araştırma Hastanesi, Ortopedi ve Travmatoloji Kliniği \\ ${ }^{2}$ LIV Hospital, Ortopedi ve Travmatoloji Kliniği, Ankara
}

\begin{abstract}
Mediyal ve lateral malleoller ayak bileği eklemi stabilitesinde önemli bir role sahiptir. Ayrı ayrı her iki malleol de kırılabileceği gibi, aynı anda birlikte de kırılabilirler. Malleol kırıklarının ne şekilde tedavi edileceklerine karar verilirken; kırık deplasmanı, talusun malleoller arasındaki uyumu, eşlik eden bağ yaralanmaları ve hastanın durumu göz önünde bulundurulmaktadır. Ayrılmamış, tibia plafonduna ulaşmayan mediyal malleol kırıkları konservatif tedavi edilebilir. Fibulanın kısalmadığı, kırığın ayrılmadığı ve sindezmoz bağlarında - deltoid bağlarda yaralanma olmadığı durumlarda, lateral malleol kırıkları da konservatif olarak tedavi edilebilir. Bu kırıklara, talus veya tibia plafondunda kıkırdak yaralanmaları eşlik edebilir. Cerrahi tedavi gerekmekte ise, ayak bileği çevresi yumuşak dokuların durumu göz önünde bulundurulmalıdır.
\end{abstract}

Anahtar sözcükler: mediyal malleol kırığı; lateral malleol kırığı; bimalleolar kırıklar; konservatif tedavi; cerrahi tedavi
Medial and lateral malleolus have an important role in ankle joint stability. Although medial and lateral malleolus can be fractured individually, they also can be fractured simultaneously. Fracture displacement, the harmony of the talus between malleolus, accompanying soft tissue injuries and general condition of the patient are all important to decide the type of treatment. If the fracture is undisplaced and the fracture line does not reach tibial plafond, medial malleolus fractures can be managed conservatively. If the fibula is not shortened, the fracture is not displaced, and if there is not accompanying syndesmosis or deltoid ligament injury, lateral malleolus fractures can be also managed conservatively. Cartilage injuries in talus or tibial plafond may accompany these fractures. The condition of the soft tissues has to be considered if there is need for surgical treatment.

Key words: medial malleolus fracture; lateral malleolus fracture; bimalleolar fracture; conservative treatment; surgical treatment

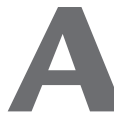

yak bileği kırıkları, tüm kırıkların \%10'unu oluşturur. ${ }^{[1-3]}$ Ortalama görülme yaşı 45'tir. ${ }^{\text {[2] }}$ Ayak bileği, talus gövdesinin mediyal malleol, tibial plafond ve distal fibula tarafından sınırlandırıldığı ve bu kemikler arasında bulunan oldukça güçlü bağlar ile stabilitenin sağlandığı bir eklemdir. Talus kemiğinin yaklaşık \%70'lik kısmı kıkırdak doku ile kaplıdır. ${ }^{[4]}$ Talus kemiğine hiçbir tendon yapışmaz. Ayak bileği ekleminin bileşenlerinden olan talus gövdesi, önde arka kısma göre daha geniştir. Bundan dolayı talus gövdesi dorsifleksiyon hareketi ile ayak bileği yuvasında sıkışır (topuk vuruşu pozisyonu) ve fibulanın dış rotasyon hareketine neden olur. Bu pozisyon talus gövdesinin ayak bileği mortisinde en stabil olduğu pozisyondur. Bunun tersine, plantar fleksiyonda ise stabilite azalmaktadır. Talus gövdesinin üst kısmı, tibia plafondu ile tam bir uyum içindedir; öyle ki, talusun 1 milimetrelik deplasmanı bile temas yüzeyini $\% 42$ oranında azaltmaktadır. ${ }^{[5]}$

Tibia ve fibula arasındaki muntazam stabilite, fibula distalinin tibia distalindeki çentiğe oturması ve sindezmotik bağların bu ilişkiyi sağlamlaştırması ile oluşur. Sindezmoz; anterior-inferior tibiofibular bağ (AiTFB), posterior-inferior tibiofibular bağ (PITFB) ve interosseöz bağ tarafından oluşturulmaktadır. Ayak bileği mediyalinde denge büyük miktarda derin (ön tibio-talar) ve yüzeyel (tibio-naviküler, tibio-kalkaneal ve tibio-talar) deltoid bağ sayesinde sağlanmaktadır. ${ }^{[6]}$ Lateral bağ kompleksi üç bileşenden oluşmaktadır; bu bileşenler, en zayıf olan ve ayak bileği burkulmaları ile sıklıkla yaralanan anterior

- Illetişim adresi: Uzman Dr. Ali Turgut, Tepecik Eğitim ve Araştırma Hastanesi, Ortopedi ve Travmatoloji Kliniği, Konak, İzmir Tel: 0232 - 4696969 / 1412 e-posta: draliturgutort@yahoo.com.tr

- Geliș tarihi: 3 Mayıs $2016 \quad$ Kabul tarihi: 3 Mayıs 2016 

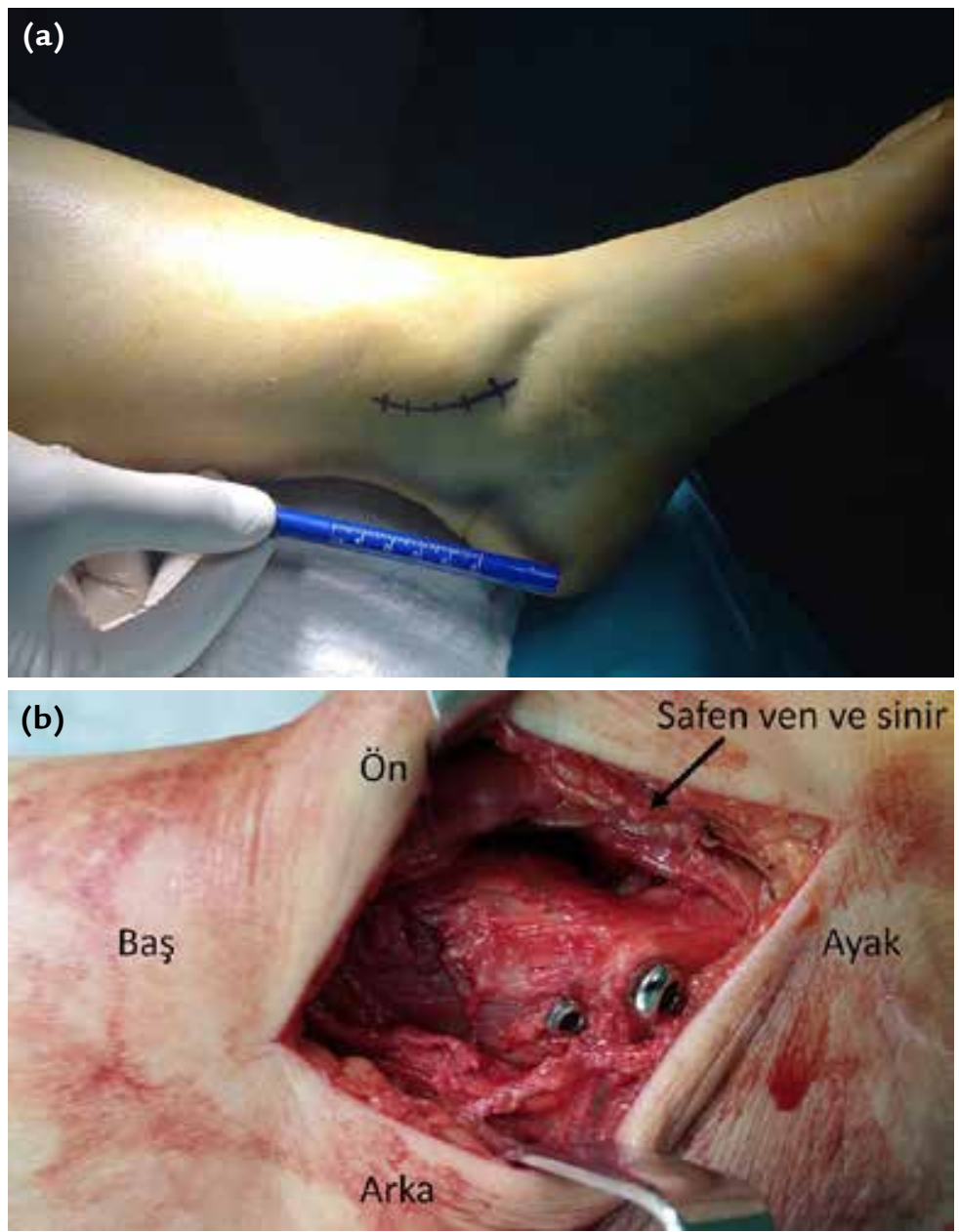

Şekil 1. a, b. Mediyal malleol kırı̆̆ına yaklaşımda standart insizyon (a). Mediyal malleolün hemen önünde yer alan safen ven ve sinir (b).

talofibular bağ, posterior talofibular bağ ve dorsifleksiyonda gerginleşen kalkaneo-fibular bağdır.

\section{Sınıflama}

Ayak bileği kırıklarında, sıklıkla Lauge-Hansen ${ }^{[7]}$ ve Danis-Weber ${ }^{[8]}$ sınıflamaları kullanılmaktadır. LaugeHansen sınıflamasında, ayağın yaralanma olduğu zamandaki pozisyonu (supinasyon-pronasyon) ve bu sırada ayağa etkiyen kuvvet (abduksiyon, adduksiyon, eversiyon) dikkate alınmaktadır. Bu sınıflandırma sisteminin, hem öğrenilmesi zordur hem de gözlemciler arası tutarlılığı sınırlıdır. ${ }^{[9,10]}$ Danis-Weber sınıflamasında ise fibula kırığının seviyesi dikkate alınmaktadır (sindezmoz altı-seviyesi-üzeri). Danis-Weber sınıflamasının, hem hatırlanması kolaydır hem de tedavi seçiminde oldukça yardımcı olmaktadır. Sınıflandırma sistemleri ile ilgili ayrıntılı bilgiye ulaşmak için lütfen ilgili bölümü okuyunuz.

\section{MALLEOL KIRIKLARINDA CERRAHI YAKLAŞIMLAR}

Ayak bileği bölgesinin cilt altı dokusu incedir ve bu bölgede kas yerine tendonlar bulunur. Bundan dolayı, özellikle yüksek enerjili yaralanmalarda yumuşak doku hasarı belirgin olabilmektedir. Hemorajik büller uyarıcı olmalıdır. Özellikle mediyal malleol kırıklarında, ayak uygun dizilimde istirahate alınmaz ise, proksimal parçanın cilde basısı sonucu nekroz oluşabilmektedir. Cerrahi tedavinin; yumuşak doku ödemi geriledikten, büller var ise iyileştikten sonra planlanması, olası yara yeri komplikasyonlarının önlenmesinde etkili olacaktır.

\section{Mediyal}

Mediyal insizyon, mediyal malleol kırıklarının redüksiyon ve tespit edilmelerinde kullanılmaktadır (Şekil 1a). İnsizyonun önünde ekstansör kas grubu (derin peroneal sinir), arkasında ise invertör-fleksör kas grubu 

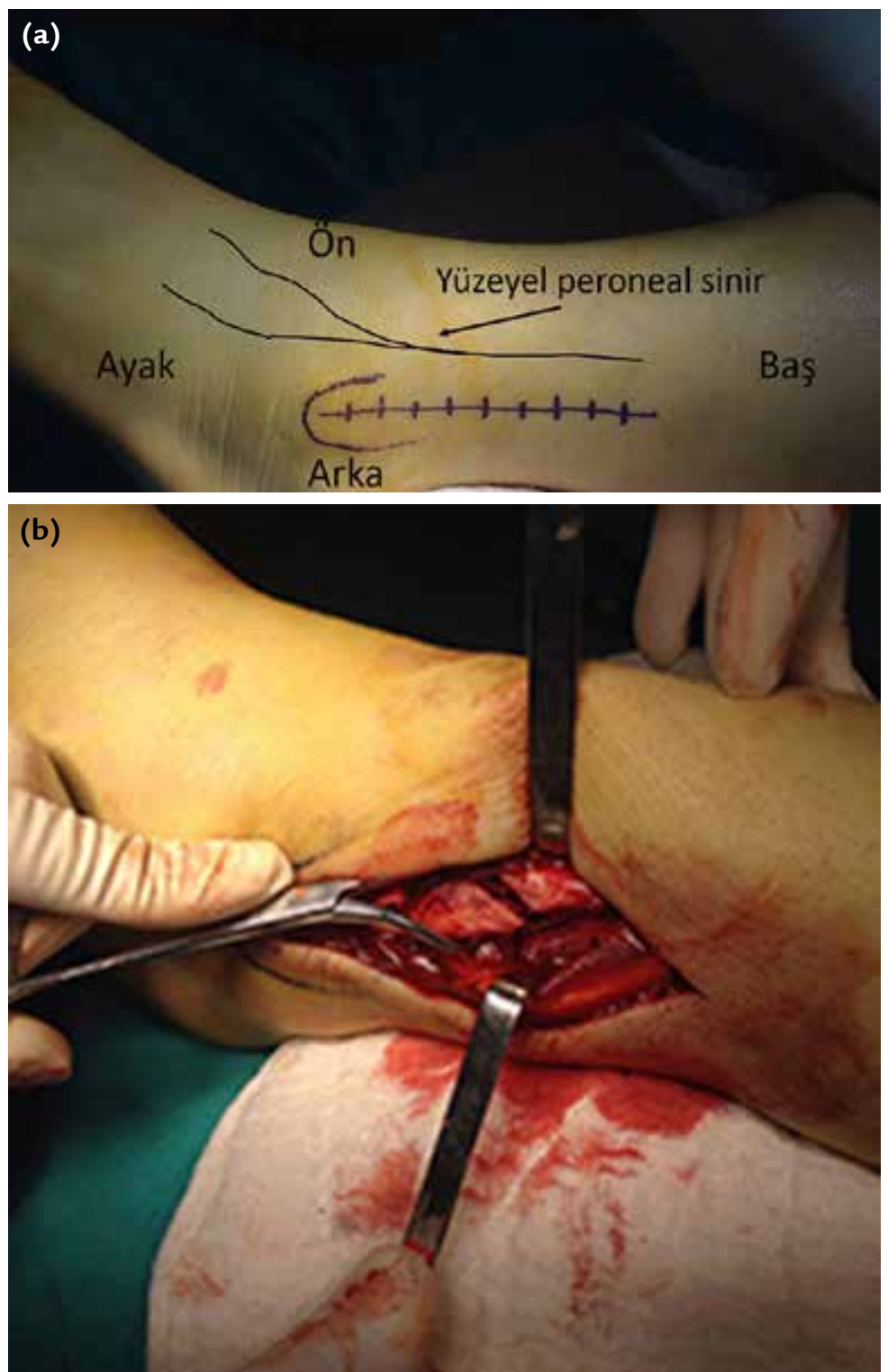

Şekil 2. a, b. Lateral malleol kırıklarında kullanılan standart insizyon (a). Lateral malleol kırığının redüksiyonu (b).

(tibial sinir) bulunmaktadır. Mediyal insizyon üç farklı şekilde yapılabilmektedir. Eklemin değerlendirilmesi isteniliyor ise insizyon biraz önden yapılmalıdır, sadece kırık redükte edilip tespit edilecek ise direkt olarak malleol üzerinden girilebilir. Arka malleol ile ilgili bir işlem yapılacak ise insizyon biraz daha arkadan yapılmalıdır. Hangi insizyon kullanılırsa kullanılsın, mediyal malleolün hemen önünde bulunan safen ven ve sinir korunmalıdır (Şekil 1b). Kırığa ulaşıldığında, hemen hemen her zaman yaralanmış periostun kırık parçalar arasında olduğu görülür. Redüksiyon öncesi periost aradan çıkarılmalıdır.

\section{Lateral}

İnsizyon yeri, kırık bölgesine ve kullanılması düşünülen plak konfigürasyonuna göre değişmektedir. Lateral plak kullanılacak ise insizyon, kapatıldığında direkt olarak plağın üzerinde kalmaması açısından fibulanın biraz önünden veya arkasından yapılmalıdır (Şekil 2a). Birlikte arka malleol tespiti yapılacak veya posterior plak kullanılacak ise posterolateral insizyon kulanılmalıdır. Sindezmozun ön kısmına veya Tillaux-Chaput parçasına ulaşılması planlanıyor ise insizyon biraz önden yapılmalıdır. Cilt insizyonu yapıldıktan sonra disseksiyonun kaslar arası planı; peroneus tertius ve 


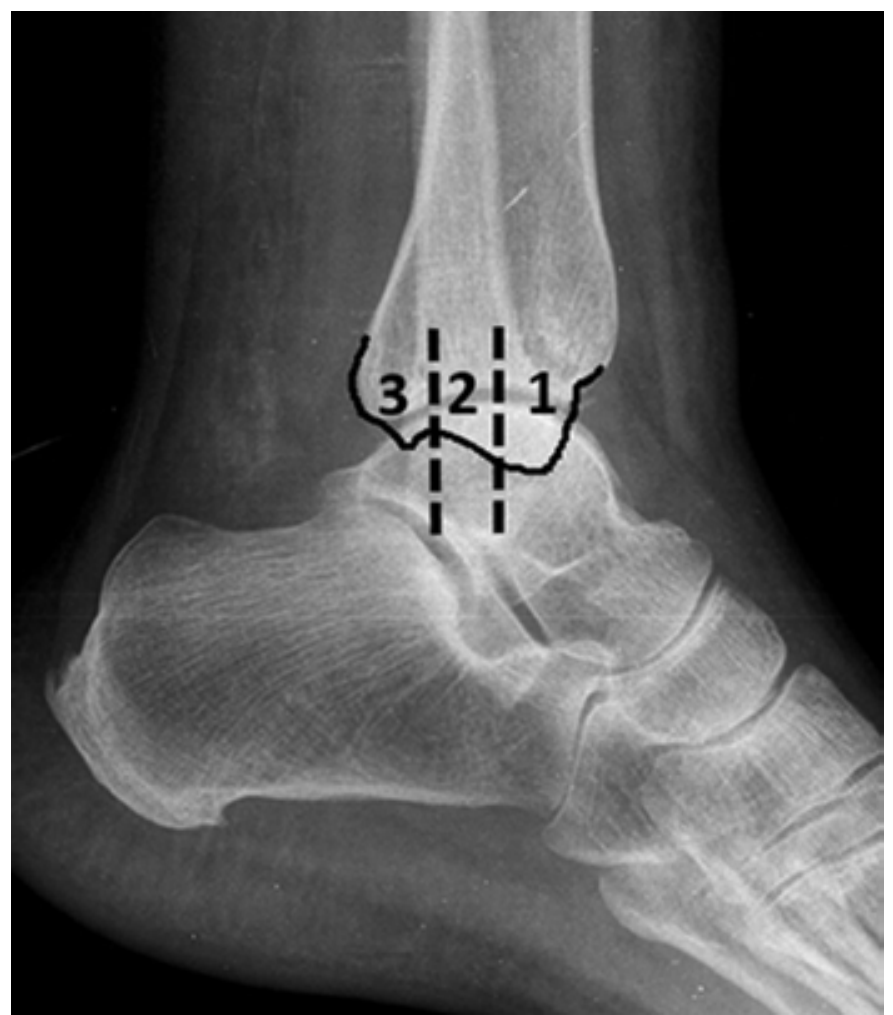

Şekil 3. Mediyal malleolde vida uygulanan bölgeler.

peroneus longus-brevis kasları arasıdır (derin peroneal sinir - yüzeyel peroneal sinir). Disseksiyon derinleştiğinde kırık hattına ulaşılır. Periost, sadece kırığın redüksiyonu değerlendirilebilecek kadar açılmalıdır (Şekil 2b). Lateralden yapılan insizyonlarda; önde yüzeyel peroneal sinir, arkada ise peroneal tendonlar, fleksor hallucis longus kası, sural sinir ve kısa safen ven risk altında bulunan yapılardır.

\section{MALLEOL KIRIKLARINDA TEDAVI}

\section{İzole Mediyal Malleol Kırığı}

Her ne kadar 1945 yılında Müller[11] tüm mediyal malleol kırıklarının cerrahi olarak tespit edilmesini önermişse de, günümüzdeki yaklaşım; kaymamış veya az miktarda kaymış ve kırık hattının tibia plafonduna ulaşmadığı izole kırıklarda altı haftalık kısa bacak alçı ile konservatif tedavinin, belirgin kayma gösteren veya kırık hattının tibia plafonduna ulaştığı kırıklarda cerrahi tedavinin daha uygun olacağı şeklindedir. ${ }^{[12]}$

Mediyal malleol kırı̆ı̆ın hangi yöntem ile tespit edileceğine karar vermede; kırık hattının oryantasyonu, kırık parçanın büyüklüğü ve hastanın yaşı etkili olmaktadır. ${ }^{[13]}$ Bu kırıkların tespitinde; kısmi yivli vidalar, tam yivli vidalar, kaymayı engelleyici plaklar ve Kirschner telleri veya vida üzerinden Weber serklaj yöntemlerinden birisi kullanılabilir. Vida ile tespit planlandığında tibia distalinde, metafizer bölgede fizis skarından sonra spongiyöz kemik kalitesinin ve dolayısı ile vida yivlerinin tutunma gücünün azaldığının bilinmesi önem arz etmektedir. Kısmi yivli vida kullanıldığında çektirme vidası tekniğinin uygulanabilmesi için tüm yivlerin kırık hattını geçmesi gerekmektedir. Kadavralarda yapılan bir biyomekanik çalışmada, 30 milimetrelik ( $\mathrm{mm}$ ) kısmi yivli veya $45 \mathrm{~mm}$ tam yivli vidaların yeterli kompresyon sağladığı gösterilmiştir. ${ }^{[14]}$ Bir başka biyomekanik çalışmada unikortikal kısmi yivli vidalar ve bikortikal tam yivli vidalar karşılaştırılmış, bikortikal tam yivli vidalar ile daha stabil bir tespit sağlandığı sonucuna varılmıştır. ${ }^{[15]}$ Kırık parça yeterince büyük ise birbirine paralel iki adet 3,5 veya 4,5 mm vida kullanılması, parça eğer iki vida kullanılması için yeterince büyük değil ise rotasyonel stabilitenin sağlanması açısından bir vida ve bir Kirschner teli (K-teli) kullanılması önerilmektedir. ${ }^{[12]}$ Mediyalde vida kullanımı sonrası oluşabilecek tibialis posterior tendon irritasyonu da merak konusudur. Bu konuda Femino ve ark. literatürdeki ilk çalışmayı yapmışlar ${ }^{[16]}$ ve lateral grafide mediyal malleolü önden arkaya 1., 2. ve 3. bölgelere ayırmışlardır (Şekil 3). Buna göre 


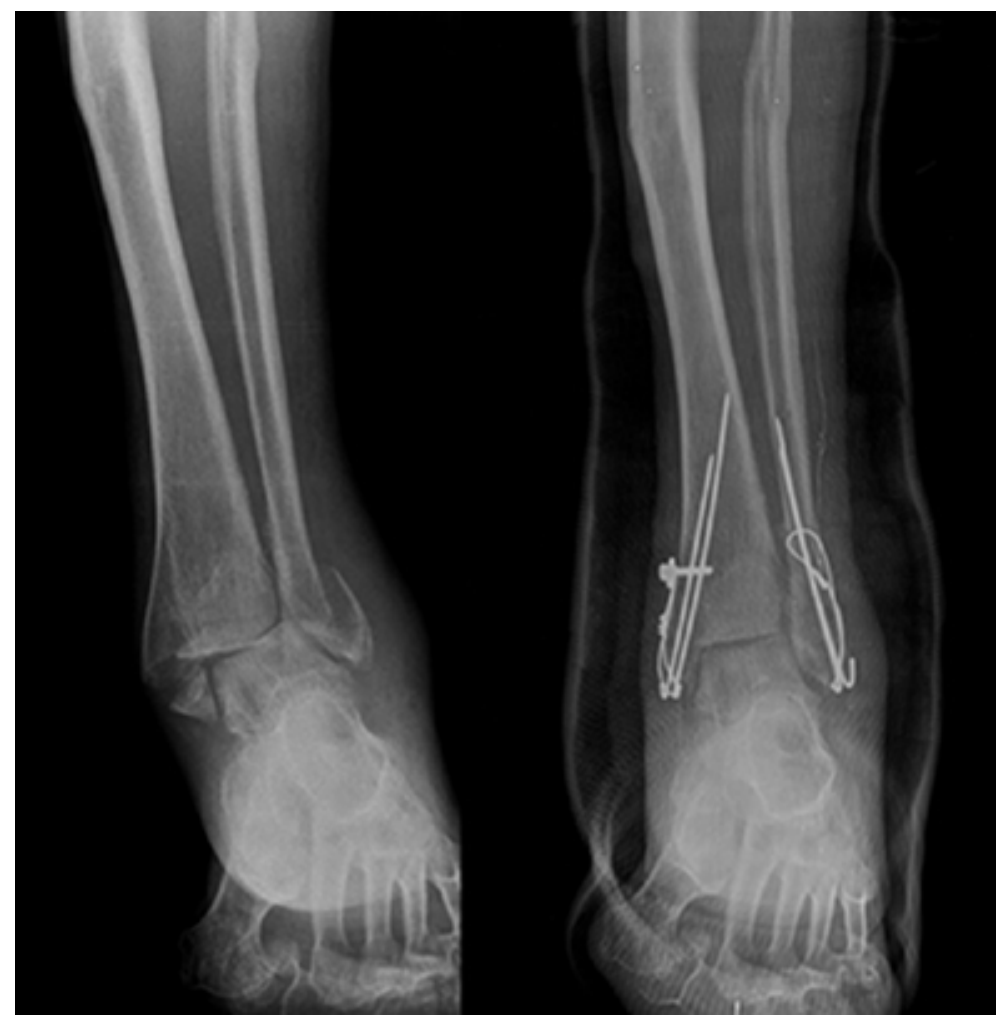

Şekil 4. Weber serklaj ile tadavi edilmiş bimalleolar kırık.

1. bölge "anterior colliculus", 2. bölge "colliculus"lar arası oluk, 3. bölge de "posterior colliculus"dur. Çalışma sonucunda; 1 . bölgenin güvenli olduğu, 2 . bölgede tibialis posterior tendonunun ortalama 2 $\mathrm{mm}$ mesafede olduğu, 3 . bölgede ise vida ve tibialis posterior tendonunun direkt olarak temas halinde olduğunu saptamışlardır. Bu çalışmaya göre vidanın 3 . bölgede kullanılması, tibialis posterior tendon irritasyonuna ve/veya hasarına neden olmaktadır. Mediyal malleolün kırık parçası vida tespiti için küçük olduğunda iki adet K-teli üzerinden Weber serklaj tekniği yeterli stabiliteyi sağlayabilir. Bu teknikte serklaj teli tibia metafizinde açılacak bir tünelden geçirilebileceği gibi, metafize uygulanan bir vida çevresinden de geçirilebilir (Şekil 4). Sıklıkla supinasyon-adduksiyon mekanizması ile oluşan ve lateral malleol kırığına eşlik eden vertikal kırıklar, en instabil olan mediyal malleol kırığı tipidir. Bu tip kırıklarda, kırığın lateralinde eklem kıkırdağının impakte olmuş olma olasılığı yüksektir (Şekil 5. a, b). Cerrahi tespitte; kırık hattına dik gönderilen tek korteksi-iki korteksi tutan vidalar veya kaymayı engelleyici plak-vida konfigürasyonu kullanılabilir. Wegner ve ark. vertikal uzanımlı mediyal malleol kırıklarında, en güçlü tespit yönteminin kayma engelleyici plak-vida olduğunu bildirmişlerdir. ${ }^{[17]}$

\section{İzole Lateral Malleol Kırığı}

\section{infrasindesmotik (Danis-Weber A) kırıklar}

Bu tip kırıklar genellikle stabil olarak kabul edilir. Dikkat edilmesi gereken durum bu tip kırık ile birlikte talusun laterale translasyonunun olmamasıdır. Deltoid bağ yaralanmasının olmadığı durumda translasyon beklenmez. Kırık deplase veya talus laterale kaymış ise kırı̆ıın cerrahi olarak tespit edilmesi yerinde olacaktır. Bu kırıkları kapalı olarak redükte etmek ve alçılama ile bu redüksiyonun devamını sağlamak çok mümkün olmamaktadır. Bu tip kırıkların cerrahi tespitinde lateralden destek plak (genellikle 1/3 tübüler plak), kanal içi vida veya K-telleri üzerinden serklaj yöntemleri kullanılabilir.

\section{Sindezmoz seviyesi (Danis-Weber B) kırıklar}

Bu kırıklar genellikle distalde önden, proksimalde arkaya doğru uzanan oblik seyirli kırıklardır. Fibula distali dışa dönmüş ve arkaya kaymış olabilir, yani fibula boyu kısalabilir. Fibulada kısalık yok ise, kırık kaymamışsa, ayak dış rotasyon stres grafisi veya yerçekimi stres grafisinde (hasta kırık tarafina dönerek lateral dekubit pozisyonda yatarken ilgili ayak bileği masanın dışında tutularak yerçekimine bırakılır ve ayak bileğinin 

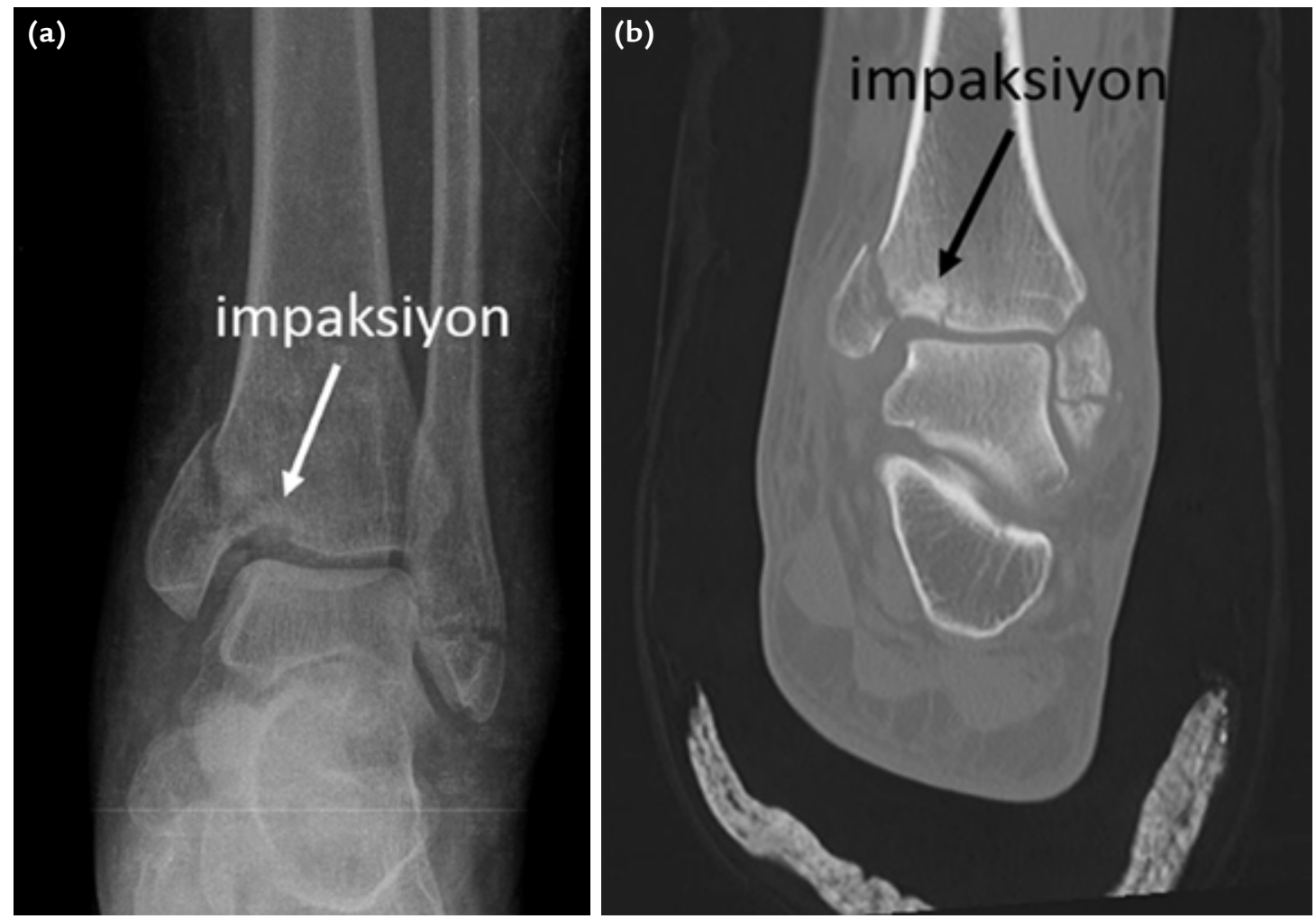

Şekil 5. a, b. Supinasyon-adduksiyon tipi yaralanmada oluşan kıkırdak yaralanması (a). Kıkırdak yaralanmasının bilgisayarlı tomografideki görünümü (b).

ön-arka grafisi çekilir) mediyal eklem aralığında açılma olmuyor ise altı haftalık kısa bacak alçı ile tedavi tercih edilebilir. Konservatif tedaviye başlanan hastalarda ilk üç hafta, haftada bir röntgen kontrolü yapılması, başlangıçta fark edilmeyebilecek lateral instabilitenin tanınmasını sağlayabilir. Fibula kısalmış ise ve/veya ayak bileği eklemi stabil değil ise cerrahi tedavi tercih edilmelidir. Bu tip kırıkların cerrahi tespitinde; lateralden veya posteriordan destek plağı, çektirme vidası ve nötralizasyon plağı, uzun oblik kırıklarda en az iki adet çektirme vidası yöntemleri kullanılabilir. Sadece çektirme vidaları kullanıldığında bu tespit, alçı ile desteklenmelidir. Bu durum da günümüzde eklem kırıklarının tedavi prensiplerinden olan erken harekete izin vermemektedir.

\section{Sindezmoz üzeri (Danis-Weber C) kırıklar}

Bu tip kırıklara bağ yaralanması eşlik etme ihtimali, diğer iki tipe göre daha çoktur. Sindezmoz seviyesindeki kırıklara benzer olarak eğer kırık kaymamış, fibula kısalmamış ise ve dış rotasyon stres grafilerinde mediyal eklem açılması yok ise (yani sindezmoz yaralanması olmadığı düşünülüyor ise) hasta konservatif olarak altı haftalık kısa bacak alçı ile tedavi edilebilir. Ancak ,yukarıda bahsedilen senaryo ile çok nadir karşılaşılmaktadır. Fibula kısalmış, kırıkta rotasyon ve/veya ayrışma var veya mortis-stress grafilerinde eklem uyumsuzluğu gözlemleniyor ise, seçilecek tedavi yöntemi cerrahi tespit olmalıdır (Şekil 6a). Basit tip kırıklarda fibula uzunluğu kolayca sağlanabiliyor iken, kırık parçalı ise uzunluğu sağlamak zor olabilir. Bu durumda; insizyon proksimale doğru normalden biraz daha geniş olarak yapılarak, kullanılan plağın 1-2 santimetre üzerinden bir adet vida serbest olarak gönderilerek vida ve plak arasına yerleştirilecek lamina açıcı ile uzunluk sağlanıp kırık distalinden plak, vida yardımı ile distal parçaya tespit edilebilir. Eğer gerekli ise sindezmoz vidası, uygun yerden plak üzerinden veya serbest olarak gönderilebilir (Şekil 6. b, c).

Özet olarak izole lateral malleol kırığı olan DanisWeber Tip A ve B yaralanmalar genel olarak konservatif tedavi edilebilirken, mediyal yaralanmanın eşlik ettiği kırıklar ve Tip C kırıklarda cerrahi tedavi sıklıkla gerekli olmaktadır. Lateral malleol kırıklarına deltoid bağ yaralanmasının eşlik ettiği durumlar "bimalleoler kırık eşdeğeri” olarak kabul edilir. Bu yaralanma şekli, genellikle supinasyon-dış rotasyon mekanizmasının son aşaması olarak karşımıza çıkmaktadır. Bu durumda 

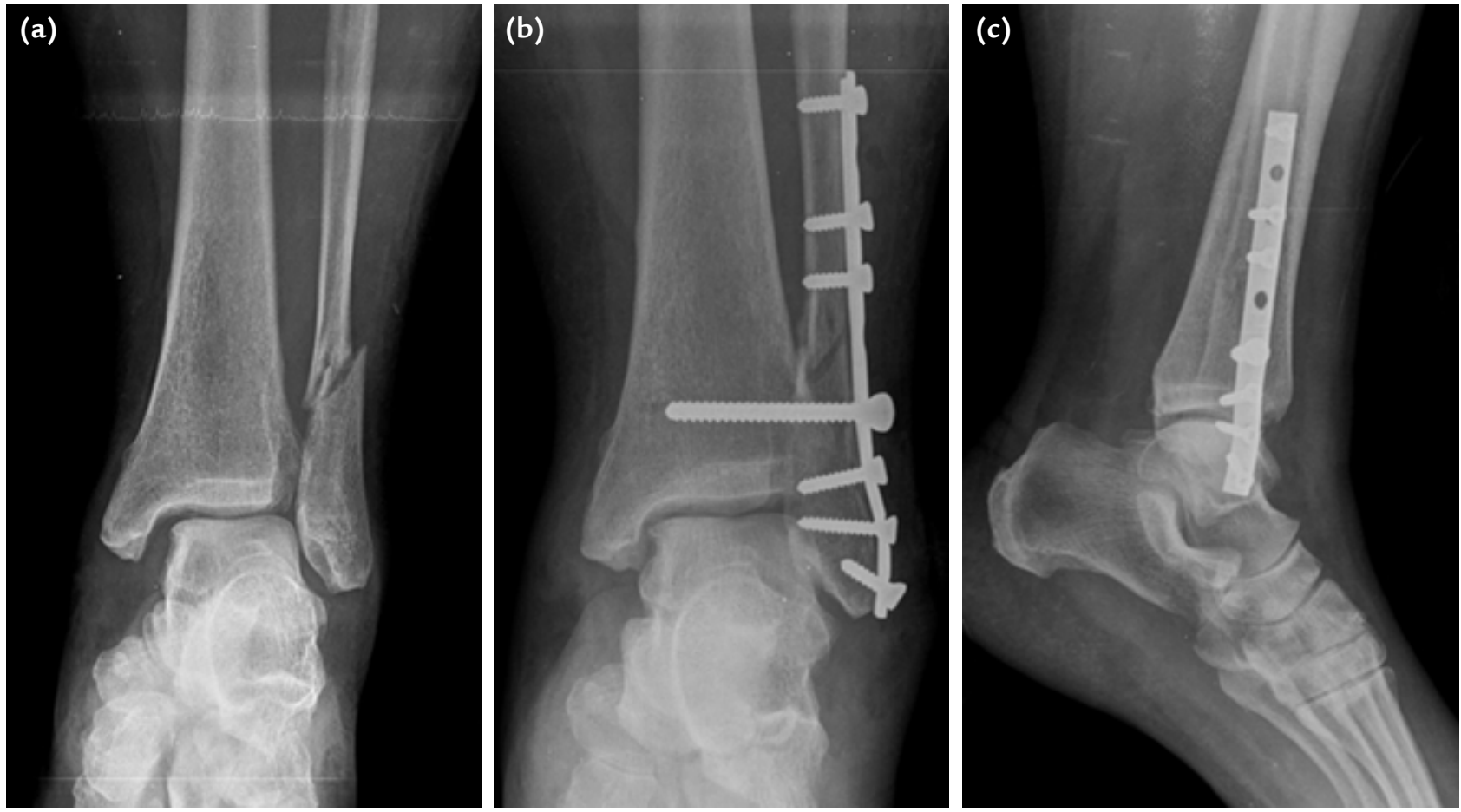

Şekil 6. a, b. Danis-Weber Tip C kırığına eşlik eden bağ yaralanması (a). Ameliyat sonrası görünüm (b).

tedavide mutlaka yapılması gerekli olan fibula kırı̆̆ının tespit edilmesidir. Fibula tespitine ek olarak sindezmoz vidası uygulaması yapılarak deltoid bağın iyileşmesi dolaylı olarak sağlanabilir. İzlenebilecek bir diğer yol da fibula tespitine ek olarak deltoid bağın onarımının yapılmasıdır. Her iki yöntemin de avantajları ve dezavantajları bulunmaktadır. Deltoid bağ onarımı yapıldığında ikinci bir insizyon yapmak gerekirken, sindezmoz vidası kullanıldığında da sindezmoz vidasının çıkarılması için ikinci bir cerrahi girişim gerekebilmektedir. ${ }^{18]}$ Klinik uygulamamız, bu tür yaralanmalarda fibula kırığının tespitine ek olarak sindezmoz vidası kullanılması şeklindedir. Sindezmoz vidası çıkarma işlemi, on hafta sonunda lokal anestezi ile yaklaşık bir santimetrelik kesiden kolayca yapılabilmektedir.

Lateral malleol kırıklarının cerrahi tespiti esnasında sindezmoz altındaki bölgede ve sindezmoz seviyesinde vidaların uzunlukları mutlaka skopi ile kontrol edilmelidir. Eğer ayak bileği ve/veya distal tibio-fibular eklemler vida ile penetre edilmişlerse, vida boyları kısaltılmalıdır.

Bu kısımda, özellik arzeden, Bosworth kırıklı çıkığına değinmek yerinde olacaktır. Bu yaralanma tipinde fibula sindezmoz seviyesi üzerinden kırılmış ve ayak bileği arkaya doğru çıkmıştır. Fibulanın proksimal kısmı, tibianın arkasına kilitlenmiştir. Ayak bileği dış rotasyonda bulunduğundan, röntgenlerde fibulanın arkada olduğunu fark etmek zor olmaktadır. Kapalı redüksiyon denemeleri çoğu zaman başarısızdır. Yapılması gereken; eklem kıkırdağına zarar vermemek için zorlayıcı manipülasyondan kaçınıp, lateralden fibulayı açık olarak redükte ederek eklemi kolayca yerleştirmektir.

\section{Mediyal ve Lateral Malleol Kırığı (Bimalleolar Kırık)}

Mediyal ve lateral malleollerin her ikisinin de kırık olduğu durumda, kırıklar kapalı olarak redükte edilebiliyor ve talusun tibia plafondu altındaki redüksiyonu sürdürülebiliyorsa, alçı ile konservatif tedavi uygulanabilir. ${ }^{[19,20]}$ Ancak, talus tibia plafondu altında anatomik olarak redükte edilemiyor veya bu redüksiyon sürdürülemiyor ise, cerrahi tedavi kaçınılmaz seçenektir. Kapalı olarak anatomik redüksiyon sağlanan kırıklarda bile erken ayak bileği hareketine başlanabilmesi için kontrendikasyon olmayan hastalarda cerrahi tedavinin seçilmesi uygundur.

Bimalleolar kırıkların cerrahi tedavisi planlanırken hangi taraftan başlanacağı halen tartışma konusudur. Çoğu cerrah, öncelikle lateral malleolün tespitini yapmayı tercih etmektedir. Unutulmaması gereken, lateral malleol tespit edildikten sonra eklem kıkırdağının mediyal insizyondan değerlendirilmesinin çok 
zor olacağıdır. Özellikle tibial plafond kıkırdağının yaralanma ihtimalinin yüksek olduğu supinasyon-adduksiyon tipi kırıklarda (Şekil 5. a, b), eklemin daha sağlıklı değerlendirilebilmesi açısından mediyal malleol cerrahisinin ilk önce yapılması yerinde olacaktır. Hangi taraftan başlanırsa başlansın, kırık redüksiyonu mümkün olmuyor ise tespit yapılmadan karşı taraftaki kırık eksplore edilmeli ve redüksiyona engel olan etken ortaya çıkarılmalıdır. Sonrasında her iki tarafta uygun redüksiyon sonrası tespit edilmelidir.

Her iki malleolü kırık olan hastalarda, kırık taraflardan biri, konservatif tedavi edilmeye uygun olacak şekilde kaymamış olabilir. Böyle bir durumda, stabil kabul edilen tarafın konservatif, diğer tarafın cerrahi olarak tedavi edilmesini öneren literatür bilgisi mevcut olmasına rağmen ${ }^{[11,21]}$, tersini savunan yazarlar da mevcuttur. ${ }^{[22,23]}$ Klinik yaklaşımımız; herhangi bir malleol kırığına eşlik eden diğer taraf malleol kırı̆̆ı veya bağ yaralanması olması durumunda, bu malleol kırığının instabil olduğu yönündedir. Dolayısı ile, bimalleolar kırıkların cerrahi tedavisinde her iki tarafın da cerrahi tespit edilmesi gerektiği düşüncesindeyiz.

\section{CERRAHI SONRASI DÖNEM}

Her ne kadar 2010 yılında yayınlanan "Ulusal Venöz Tromboembolizm Profilaksi ve Tedavi Kılavuzu"nda diz altı bölgelerin izole yaralanmalarında rutin profilaksi önerilmemekte ise de, literatür ${ }^{[24]}$ risk faktörü olan hastalarda (obezite, diyabet, tromboemboli özgeçmişi, immobilizasyon, oral kontraseptif kullanımı vb.) kontrendikasyon yok ise profilaksi yapılmasını önermektedir.

Konservatif tedavi edilen hastalarda önerilen alçı süresi altı haftadır. Cerrahi tespit yapılan hastalarda immobilizasyon süresi, şekli ile ilgili bir görüş birliği yoktur. Klinik uygulamamı; ameliyat esnasında kazanılan stabilite yeterli, kemik kalitesi iyi olan hastalarda, iki hafta kısa bacak alçı atel sonrası yük vermeden pasif-aktif eklem hareketlerine başlamak, osteoporotik veya stabilite konusunda emin olunamayan hastalarda ise altı hafta kısa bacak alçı atel uygulanması şeklindedir. Ameliyat sonrası hastalara, literatür ile uyumlu olarak, altıncı haftadan sonra yük verdirmekteyiz. ${ }^{[25]}$

Hastaların ameliyat sonrası araba kullanma zamanı ile ilgili yapılan çalışma göstermiştir ki; immobilizasyon uygulanan hastaların pedal reaksiyon zamanları belirgin olarak uzamıştır. ${ }^{[26]} \mathrm{Bu}$ durum, alçı veya atel çıkarıldıktan sonra üç hafta daha devam etmektedir. Dolayısı ile, ameliyat edilen hastaların araba kullanmalarına alçı çıkarıldıktan üç hafta sonra izin verilmelidir.

\section{KAYNAKLAR}

1. Bengnér $U$, Johnell $O$, Redlund-Johnell I. Epidemiology of ankle fracture 1950 and 1980. Increasing incidence in elderly women. Acta Orthop Scand 1986;57(1):35-7.

2. Court-Brown CM, McBirnie J, Wilson G. Adult ankle fractures -an increasing problem? Acta Orthop 1998;69(1):43-7.

3. Daly PJ, Fitzgerald RH, Melton LJ, Ilstrup DM. Epidemiology of ankle fractures in Rochester, Minnesota. Acta Orthop Scand 1987;58(5):539-44.

4. Goss CM, editor. Gray's Anatomy, 29th ed. Philadelphia, PA. Lea \& Febiger; 1973.

5. Ramsey PL, Hamilton W. Changes in tibiotalar area of contact caused by lateral talar shift. J Bone Joint Surg Am 1976;58(3):356-7.

6. EarllM,WayneJ,BrodrickC,VokshoorA,AdelaarR. Contribution of the deltoid ligament to ankle joint characteristics: a cadaver study. Foot Ankle Int 1996;17(6):317-24.

7. Lauge N. Fractures of the ankle: analytic historic survey as basis of new experimental, roentgenologic and clinical investigations. Arch Surg 1948;56(3):259-317.

8. Weber BG. Die Verletzungen des oberen Sprunggelenkes. Bern: Verlag Hans Huber; 1977.

9. Nielson JO, Dons-Jensen H, Sorensen HT. Lauge-Hansen classification of malleolar fractures. An assessment of the reproducibility in 118 cases. Acta Orthop Scand 1990;61(5):385-7.

10. Rasmusen S, Madsen PV, Bennicke K. Observer variation in the Lauge-Hansen classification of ankle fractures. Precision improved by instruction. Acta Orthop Scand 1993;64(6):693-4.

11. Muller GM. Fractures of Internal Malleolus. $\mathrm{Br}$ Med J 1945;2(4418):320.

12. White TO, Bugler KE. Ankle fractures. In: Court-Brown CM, Heckman JD, Mc Queen MM, Ricci WM, Tornetta P, McKee MD, editors Rockwood and Green's Fractures in Adults, 8th ed. Wolters Kluwer; 2015. p.2542-91.

13. King CM, Cobb M, Collman DR, Lagaay PM, Pollard JD. Bicortical fixation of medial malleolar fractures: a review of 23 cases at risk for complicated bone healing. J Foot Ankle Surg 2012;51(1):39-44. Crossref

14. Parker L, Garlick N, McCarthy I, Grechenig S, Grechenig W, Smitham P. Screw fixation of medial malleolar fractures: a cadaveric biomechanical study challenging the current $\mathrm{AO}$ philosophy. Bone Joint J 2013;95-B(12):1662-6. Crossref

15. Ricci WM, Tornetta P, Borrelli J Jr. Lag screw fixation of medial malleolar fractures: a biomechanical, radiographic, and clinical comparison of unicortical partially threaded lag screws and bicortical fully threaded lag screws. J Orthop Trauma 2012;26(10):602-6.

16. Femino JE, Gruber BF, Karunakar MA. Safe zone for the placement of medial malleolar screws. J Bone Joint Surg 2007;89(1):133-8.

17. Wegner AM, Wolinsky PR, Robbins MA, Garcia TC, Maitra $S$, Amanatullah DF. Antiglide plating of vertical medial malleolus fractures provides stiffer initial fixation than bicortical or unicortical screw fixation. Clin Biomech (Bristol, Avon) 2016;31:29-32. Crossref

18. Jones CR, Nunley JA 2nd. Deltoid ligament repair versus syndesmotic fixation in bimalleolar equivalent ankle fractures. J Orthop Trauma 2015;29(5):245-9. Crossref

19. Joy G, Patzakis MJ, Harvey JP Jr. Precise evaluation of the reduction of severe ankle fractures. J Bone Joint Surg Am 1974;56(5):979-93. 
20. Dietrich $A$, Lill $H$, Engel $T$, Schönfelder $M$, Josten $C$. Conservative functional treatment of ankle fractures. Arch Orthop Trauma Surg 2002;122(3):165-8.

21. Hoelsbrekken SE, Kaul-Jensen $K$, Mørch T, Vika $H$, Clementsen T, Paulsrud $\varnothing$, Petursson G, Stiris M, Strømsøe $\mathrm{K}$. Nonoperative treatment of the medial malleolus in bimalleolar and trimalleolar ankle fractures: a randomized controlled trial. J Orthop Trauma 2013;633-7. Crossref

22. Svend-Hansen $\mathrm{H}$, Bremerskov $\mathrm{V}$, Baekgaard N. Ankle fractures treated by fixation of the medial malleolus alone. Late results in 29 patients. Acta Orthop Scand 1978;49(2):211-4.

23. Tornetta P 3rd. Competence of the deltoid ligament in bimalleolar ankle fractures after medial malleolar fixation. J Bone Joint Surg Am 2000;82(6):843-8.
24. Manafi Rasi A, Kazemian G, Emami Moghadam M, Tavakoli Larestani R, Fallahi A, Nemati A, Nazari M, Fallahi F, Safari S. Deep vein thrombosis following below knee immobilization: the need for chemoprophylaxis. Trauma Mon 2013;17(4):367-9. Crossref

25. Swart E, Bezhani H, Greisberg J, Vosseller JT. How long should patients be kept non-weight bearing after ankle fracture fixation? A survey of OTA and AOFAS members. Injury 2015;46(6):1127-30. Crossref

26. Egol KA, Sheikhazadeh A, Mogatederi S, Barnett A, Koval KJ. Lower-extremity function for driving an automobile after operative treatment of ankle fracture. J Bone Joint Surg Am 2003;85-A(7):1185-9. 